\title{
Tuberculin reactivity as a predictor of survival time in inoperable bronchial carcinoma
}

\author{
N J C SNELL \\ From the Central Chest Clinic, Reading, Berkshire, UK ${ }^{1}$
}

ABSTRACT One hundred and two patients with inoperable bronchial carcinoma who had tuberculin tests at the time of diagnosis were followed up to see if there was any correlation between their degree of tuberculin reactivity and their subsequent survival time. There was a significant difference in survival between positive and negative tuberculin reactors (Log Rank Test $P<0.05)$, the former having a median survival time almost twice that of the latter. This did not appear to be related to clinical differences between the groups at the time of testing, and other possible explanations are discussed. Tuberculin testing may be useful in helping to assess prognosis in patients with inoperable bronchial tumours.

This paper looks retrospectively at a group of patients with inoperable bronchial carcinoma, who were tested with both Mantoux and TB Tine tests (Lederle) as part of a comparative trial of the two methods of tuberculin testing, to see if the degree of tuberculin reactivity at the time of diagnosis had any predictive value regarding subsequent survival time.

\section{Methods}

All patients admitted to the Reading Chest Unit over a two-year period had simultaneous Mantoux (10 TU) and Tine tests performed on them, which were read 48 to 72 hours later by the same observer. Out of these patients, 113 had a diagnosis of primary bronchial carcinoma; after excluding patients on corticosteroids at the time of testing (one) and those submitted to "curative" surgery (10), 102 patients ( 89 male, 13 female) were left for analysis. Forty-two patients had squamous cell tumours, 13 oat cell tumours, nine adenocarcinomas, five anaplastic tumours, and one alveolarcell carcinoma; 13 others had histological or cytological proof of diagnosis but no details in their records except "bronchial carcinoma." Nineteen were diagnosed on clinical and radiological grounds only and have subsequently died.

The tuberculin tests were read as recommended in The Diagnostic Standards and Classification of Tuberculosis (National Tuberculosis Association,

1Present address: MRC Tuberculosis and Chest Diseases Unit, Brompton Hospital, Fulham Road, London SW3.
1969). For the Mantoux test less than $5 \mathrm{~mm}$ induration was taken as negative; 5-9 $\mathrm{mm}$, doubtful positive; and $10 \mathrm{~mm}$ or more, positive. For the Tine test, less than $2 \mathrm{~mm}$ induration at any of the Tine puncture sites was taken as negative; $2-4 \mathrm{~mm}$ as doubtful positive; and $5 \mathrm{~mm}$ or more as positive. Correlation between the two tests was good with the Tine batch used; percentage agreement in these patients was $74 \%$, rising to $89 \%$ if doubtful positive readings were taken as positive reactions. Where there was disagreement between the tests the more reactive of the two was taken as the true reading since for the purposes of this investigation it could be assumed that false-positive reactions did not occur.

\section{Results}

Applying the above criteria, there were 44 positive and 48 negative reactors, with 10 classified as doubtful positives. When this paper was prepared, 92 patients had died and 10 still survived (four positive, three doubtful, and three negative).

The survival times of all the patients are shown in fig 1 , and the actuarial survival curves for the positive and negative reactors in fig 2 . The median survival time of the positive reactors was 25 ㄱ weeks, and of the negative reactors 13.5 weeks. The Log Rank Test (Peto et al, 1977) showed a significant difference in the survival curves $\mathbb{D}$ $(\mathrm{P}<0.05)$. In round terms, of the positive reactors, nearly one-half $(48 \%)$ survived for six months and more than one-quarter $(27 \%)$ for one year: of 


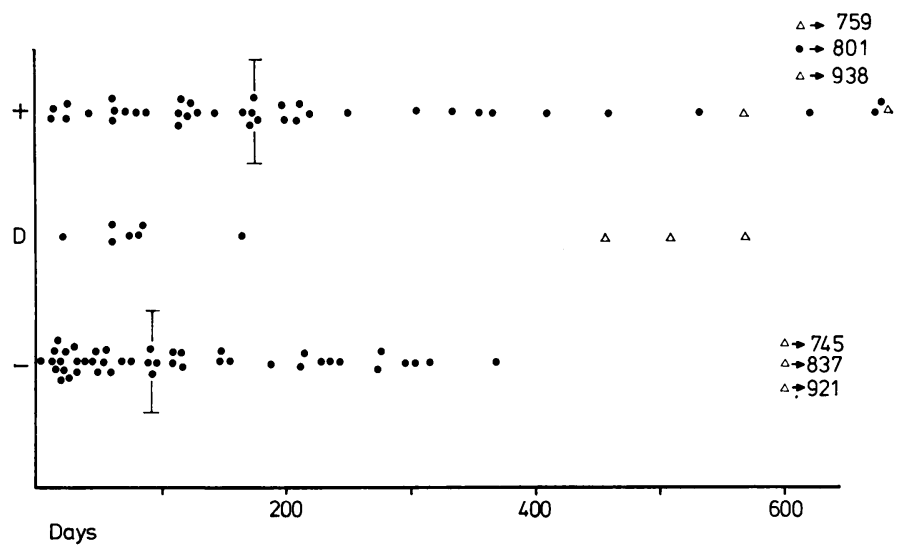

Fig 1 Survival times of all patients; + positive reactors, $\mathrm{D}$ doubtful reactors, - negative reactors, $\bullet$ deceased, $\Delta$ still alive, and median values are shown $I$.

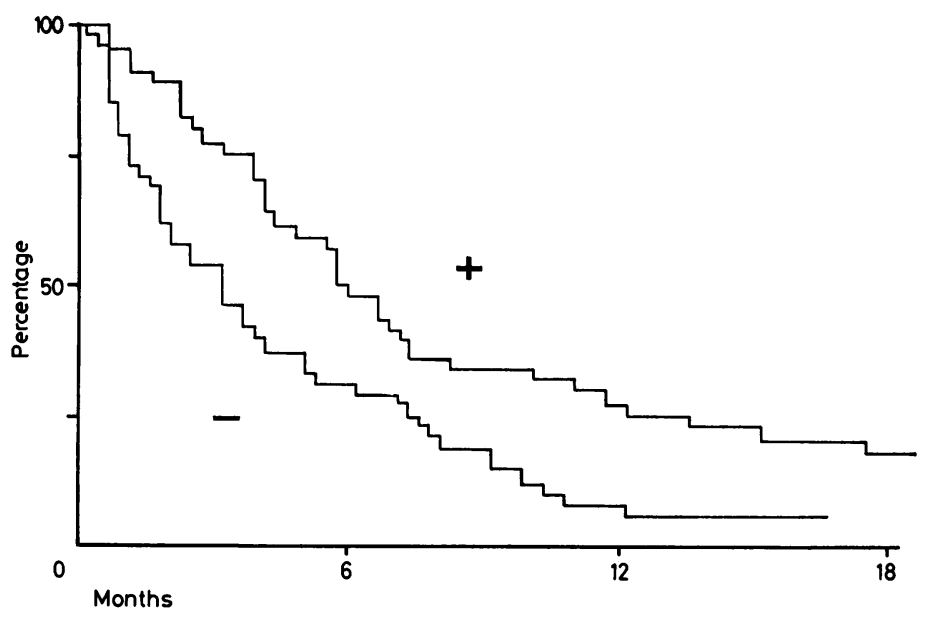

Fig 2 Survival curves for positive $(+)$ and negative $(-)$ reactors.

the negative reactors just under one-third $(31 \%)$ survived for six months, and only $8 \%$ for one year. This advantage in mortality rate for the positive reactors was evident at all stages throughout the first year of follow-up.

The doubtful positive group was too small to analyse separately: including them in the positive category gave a median survival time of 24.5 weeks instead of 25; the Log Rank Test was unchanged $(\mathrm{P}<0 \cdot 05)$.

Interestingly, survival time in the positive reactors was not significantly related to the size of the reaction; patients with Mantoux reactions of less than $15 \mathrm{~mm}$ and Tine reactions of less than $10 \mathrm{~mm}$ had a median survival time only one week less than those with Mantoux reactions greater than $15 \mathrm{~mm}$ and Tine reactions greater than $10 \mathrm{~mm}$.

\section{Discussion}

These results show that positive tuberculin reactivity carried a substantial advantage in survival time in this group of patients with inoperable bronchial carcinoma. There are several possible explanations for this finding.

Firstly, the positive and negative groups might not have been comparable clinically. In the table the objective clinical state of both groups, as described in the clinical notes at the time of tuberculin testing, is compared. (The notes were incomplete or not specific in some cases.) The groups are generally comparable clinically and in respect of treatment received; the only significant differences between them are in the mean ages $(61.8$ years against 68.7 years; $p<0.001)$ and in the sex distribution. The clinical significance of this is debatable 
Clinical state of patients $(\%$ in parentheses) at time of testing

\begin{tabular}{lcl}
\hline & Positive reactors & Negative reactors \\
\hline Men & 41 & 38 \\
Women & 3 & 10 \\
Mean ages & $61 \cdot 8$ & $68 \cdot 7$ \\
Squamous cell tumour & $19(43 \cdot 0)$ & $17(39 \cdot 0)$ \\
Oat cell tumour & $5(11 \cdot 0)$ & $7(14 \cdot 0)$ \\
Adenocarcinoma & $3(7 \cdot 0)$ & $7(14 \cdot 0)$ \\
Anaplastic tumour & $0(0)$ & $4(8 \cdot 0)$ \\
Alveolar cell carcimona & $1(2 \cdot 0)$ & $0(0)$ \\
Carcinoma, type unspecified & $8(16 \cdot 0)$ & $6(13 \cdot 0)$ \\
Carcinoma, no histology & $9(20 \cdot 0)$ & $8(17 \cdot 0)$ \\
Evidence of metastases & $13(29 \cdot 5)$ & $13(27 \cdot 0)$ \\
Paralysed hemidiaphragm & $5(11 \cdot 4)$ & $2(4 \cdot 2)$ \\
Pleural effusion & $2(4 \cdot 5)$ & $6(12 \cdot 5)$ \\
S V C obstruction & $1(2 \cdot 3)$ & $3(6 \cdot 3)$ \\
Hypercalcaemia & $1(2 \cdot 3)$ & $2(4 \cdot 2)$ \\
Laryngeal nerve palsy & $1(2 \cdot 3)$ & $1(2 \cdot 1)$ \\
Horner's syndrome & $1(2 \cdot 3)$ & $0(0)$ \\
Treated with radiotherapy & $10(22 \cdot 7)$ & $12(25)$ \\
Treated with chemotherapy & $3(6 \cdot 8)$ & $2(4 \cdot 2)$ \\
Radiotherapy and & & \\
\multicolumn{1}{c}{ chemotherapy } & $4(9 \cdot 1)$ & $3(6 \cdot 3)$ \\
& & \\
\hline
\end{tabular}

since the poorer survival rate in the negative reactors is not explicable on the basis of particularly short survival of women or of elderly patients. Similarly, the negative group contained four patients with anaplastic tumours as against none in the positive group, but perhaps surprisingly these patients improved rather than lowered the overall negative reactor survival rate.

Secondly, a reasonable hypothesis is that previous exposure to tuberculosis conveys an advantage in survival in patients subsequently developing bronchial cancer. Springett (1971) has shown that men diagnosed in 1959 as having pulmonary tuberculosis subsequently had a higher than expected death rate from lung cancer, and Stott $e t$ al (1976) showed no overall difference in cancer deaths between tuberculous patients diagnosed between 1950-7 and followed up for a mean period of over 19 years, and the general population. It is difficult to imagine a mechanism that, while having no beneficial effect on the chance of developing cancer, would enhance survival once malignancy was established.

Excluding these two possibilities, the likely explanation of these results is that positive tuberculin reactivity is being used in this situation as a nonspecific indicator of an intact cell-mediated immune system, thereby implying a good host response against malignant cells in these patients. The converse of course is not necessarily true; some negative reactors may have good cell mediated immunity but happen never to have been sensitised to mycobacterial antigens. This might explain some of the longer survival times in the negative group; testing with a more universally experienced antigen might give more clearly de- $\frac{\vec{O}}{0}$ fined results.

Reversion of tuberculin reactivity from positive $\frac{\bar{\sigma}}{\bar{c}}$ to negative during the course of malignant disease $\stackrel{\mathbb{Q}}{\propto}$ has been well documented (Hughes and MacKay, 1965; Krant et al, 1968; Bonchek, 1971). There is some evidence that this may be due to active inhibition of immune responses (Blomgren et al, $\overrightarrow{\vec{\omega}}$ 1976) rather than to general debility; Israel et al $\stackrel{\omega}{\circ}$ (1968) have shown that the proportions of positive $\vec{x}$ and negative reactors in patients with localised $\underset{\omega}{\omega}$ and disseminated malignant disease are similar.

There has been little published work on the prognostic value of tuberculin testing in bronchial $\infty$ carcinoma. Krant et al (1968) noted that $23 \%$ of 음 their patients at diagnosis were tuberculin positive, but that positive reactors made up $35 \%$ of their long-term survivors, suggesting an advantage in survival for positive reactors. Israel et al (1973) $\stackrel{\text { क }}{\rightarrow}$ looked at 323 patients with squamous carcinomas $\overrightarrow{0}$ who underwent surgical resection of their tu- 0 mours; the median survival time of positive tuberculin reactors was 16 months, of negative reactors 8.6 months. The same trend was evident with oat cell and adenocarcinoma patients. Some of these patients showed reversion of their tuberculin re- $\frac{0}{\mathrm{D}}$ activity from negative to positive after tumour re- $\varrho$ section, and had a better prognosis than those in $\overline{\overline{0}}$ whom tuberculin testing remained negative. It is 3 interesting therefore, in view of this observable superiority in survival time for positive tuberculin reactors, that Chahinian (1972) could show no significant difference in tumour size doubling time $\frac{\text { Q }}{\Omega}$ (measured radiographically) between positive and $\times$ negative reactors with lung cancer.

The observation that positive tuberculin reactors survive longer on average than negative reactors is of considerable theoretical interest in view of the current enthusiasm for immunostimulant treat- $J$ ment in malignant disease. Tuberculin testing is $\frac{7}{2}$ simple to perform and might be a useful component of a prognostic index for patients with inoperable disease.

I am grateful to Drs D Foskett and A J Karlisho for permission to study their patients and too Messrs P Fayers and R Stephens for their advice and help with the statistical analyses.

\section{References}

Blomgren, H, Baral, E, Petrini, B, and Wasserman, J0 (1976). Impaired lymphocyte responses to PPD tuberculin in advanced breast carcinoma. Clinicalo Oncology, 2, 379-392. 
Bonchek, L (1971). Diagnosis of lung cancer in tuberculous patients. Chest, 60, 256-259.

Chahinian, P (1972). Relationship between tumor doubling time and anatamoclinical features in 50 measurable pulmonary cancers. Chest, 61, 340-345.

Hughes, L, and MacKay, W (1965). Suppression of the tuberculin response in malignant disease. British Medical Journal, 2, 1346-1348.

Israel, L, Bouvrain, A, Cros-Decam, J, and Mugica, J (1968). Contribution a l'étude des phénomènes d'immunité cellulaire chez les cancéreux pulmonaires avant traitment palliatif ou chirurgical. Le Poumon et le Coeur, 24, 339-350.

Israel, L, Mugica, J, and Chahinian, P (1973). Prognosis of early bronchogenic carcinoma. Survival curves of 451 resected lung cancer cases in relation to the results of the pre-operative tuberculin skin test. Biomedicine: Express, 19, 68-72.

Krant, M, Manskopf, G, Brandrup, C, and Madoff, $M$ (1968). Immunologic alterations in bronchogenic cancer. Cancer, 21, 623-631.
National Tuberculosis Association (1969). Diagnostic Standards and Classifications of Tuberculosis, 12th edn. NTA, New York.

Peto, R, Pike, M, Armitage, P, Breslow, N, Cox, D, Howard, S, Mantel, N, McPherson, K, Peto, J, and Smith, P (1977). Design and analysis of randomised clinical trials requiring prolonged observation of each patient; II Analysis and Examples. British Journal of Cancer, 35, 1-39.

Springett, V (1971). Ten-year results during the introduction of chemotherapy for tuberculosis. Tubercle, 52, 73-87.

Stott, H, Peto, J, Stephens, R, Fox, W, Sutherland, I, Foster-Carter, A, Teare, H, Fenning, J (1976). An assessment of the carcinogenicity of isoniazid in patients with pulmonary tuberculosis. Tubercle, 57, $1-15$.

It is regretted that no reprints of this paper are available. 